\title{
Trends and Determinants of Lifelong Learning: Regional Differences in Europe
}

\author{
Buryk Zoriana, Orliv Mariana, Karen Ismailov
}

\begin{abstract}
The article analyzes lifelong learning indicators and trends in 33 European countries (EU member countries as well as Norway, Switzerland, Iceland, Macedonia and Serbia) based on Eurostat and World Bank data for 2002-2017. The problems of determining qualitative indicators of lifelong learning as well as monitoring and analysis of learning outcomes are revealed. The necessity for the creation of countries' own information systems, in which the data are detailed by age and gender, types of education, learning and development methods is substantiated.

The correlation analysis of the following quantitative indicators is carried out: early leavers from education and training, tertiary educational attainment, young people neither in employment nor in education and training, employment rates of recent graduates, adult participation in learning, formal and non-formal education and training participation, GDP per capita. Regional differences in life-long learning trends in Europe are identified by the method of tree clustering. The quality of the differentiation is iteratively optimized by the K-Means method. Three clusters of countries are distinguished which essentially differ in the following parameters: tertiary educational attainment, employment rates of recent graduates, adult participation in learning.

Determinants of the lifelong learning development are analyzed in the context of achieving the sustainable development goals. The propositions on priorities in elaboration of the further lifelong learning policy for each clusters are substantiated, taking into account the need to adhere to the principles of social justice and economic efficiency.
\end{abstract}

Keywords: lifelong learning, adult education, sustainable development, training, formal education, non-formal education, clasters.

\section{INTRODUCTION}

In the context of globalization, the rapid development of information and communication technologies (ICT) and the update of professional knowledge, the global trend of sustainable social development is the introduction of lifelong learning.

Revised Manuscript Received on November 15, 2019

* Correspondence Author

Buryk Zoriana *, Doctor of science in Public Administration, senior lecturer of Regional management and Local Self-Government Department, Lviv Regional Institute for Public Administration of the National academy for Public Administration under the President of Ukraine, Email: z.burik@ukr.net, Tel: +3-80679994240

Orliv Mariana'Ph.D in Economics, docent of the Department of Public Administration and Management, Ivano-Frankivsk National Technical University of Oil and Gas

Karen Ismailov, Candidate of Juridical Sciences, Head of Department, Odessa State University of Internal Affairs

Department of Cyber security and information support
Recognizing it as a public good, the driving force of social progress and an important condition for the implementation of all sustainable development goals (SDG), the participants of the world forum on education (May 2015, Incheon, Republic of Korea) formed the new vision of education - "Ensure inclusive and equitable quality education and promote lifelong learning opportunities for all". This approach emphasizes the role of continuing education in the socio-political, economic and cultural dimensions. In the first dimension it is defined as a prerequisite and tool for the development of socio-political systems, in the second dimension - as a factor of economic growth, in the third dimension - as a tool for the development, preservation and transmission of culture [1].

In the Incheon Declaration [2] education throughout life has an important role in poverty reduction, implementation of the humanistic concept of education and development, achievement of social justice. However, the provisions concerning adult education do not define effective mechanisms of system implementation of "training-for-growth". According to experts, the essential of adult education in the SDGs is to ensure that "no one is left behind". Only adult literature and vocal education are excerpted as clear targets related to adults (and part of the target related to gender equality), which threatens the success of the balanced implementation of the entire SDG agenda, since achieving several other goals does depend on extensive use of adult education [3].

Adult education cannot be reduced to "culture of inertia", it should focus on building intellectual, social and creative components of human capital, which is the main determinant of economic growth and innovative development of states. The policy of introducing adult education should ensure the continuity of their personal and professional development by creating conditions for the widespread use of non-formal education (non-formal education), in particular on-the-job education. After all, the results of 38 international studies in the field of education in the workplace show that this form of education can increase employee productivity by 10 percent or more, which is larger than the return on investment in physical capital [4].

The main object of the study is to analyze the statistical indicators of lifelong learning in Europe, to cluster the countries based on its results, and to identify the priorities of their further educational policy in the context of achieving the sustainable development goals.

\section{MATERIALS AND METHODS}

\subsection{Empirical base of research}

33 European countries were chosen for the study, including $28 \mathrm{EU}$ member states, as well as Norway, Switzerland, Iceland, Macedonia and Serbia. Eurostat 
and World Bank data for 2002-2017 provided the main empirical basis for the analysis. Methods of statistical and correlation analysis were used to identify the main trends and determinants of life-long learning. The method of tree clustering and K-Means clustering was used to study the regional aspects of lifelong learning.

\subsection{Methods of research}

Correlation analysis was used to determine the statistical relationship between the indicators on the basis of a sample of observations and to assess the relationship between the studied objects and processes. The main indicators for correlation analysis and clustering are as follows: Young people neither in employment nor in education and training, $\%$ of population aged 15 to 29 (YPNonEmpNorEduc); GDP per capital; Generic programs and qualifications, non-formal education and training, \% of all hours spent by adults aged 25-64 on education (PQNonform), Non-formal education and training, $\%$ of all hours spent by adults aged 25-64 on education (EducNonForm); Adult participation in learning, $\%$ of population aged 25 to 64 (Apar); Early leavers from education and training, \% of population aged 18 to 24 (Eleave); Tertiary educational attention, $\%$ of population aged 30 to 34 (Tert); Employment rates of recent graduates, \% of population aged 20 to 34 with at least upper-secondary education (EmpRateRecGrad). Calculations were carried out in Statistica 7 software.

The method of tree clustering is used for the purpose of visual allocation of the number of clusters of countries on the selected indicators on the basis of a certain measure of similarity and distance between objects in multidimensional space.

The K-Means method is used to detect grouping in data and to build clusters. The quality of the separation was iteratively optimized based on the results of calculation of the Sum of Squared Errors (SSE) according to the formula 1 [5]:

$$
S S E(C)=\sum_{j=1}^{K} \sum_{i=1}^{n_{j}}\left\|x_{i}^{j}-c_{i}\right\|^{2}
$$

\section{RESULTS}

\subsection{Regional differences of lifelong learning indicators in Europe}

In 2017 , the proportion of the population aged 18-24 who finished education, in the EU decreased by $6.3 \%$ compared to 2002 and reached the level of $10.7 \%$ [6], which is a significant achievement. In Switzerland, this figure is even lower - about $5 \%$.

According to the statistical service Eurostat in European countries selected for analysis about $45 \%$ of adults aged 25-64 participated in some form of education or training [7]. The highest rates were recorded in Switzerland (69.1\%), the Netherlands $(64.1 \%)$, Sweden $(63.8 \%)$ and Norway $(60 \%)$, which at the end of 2017 entered the top ten of the world in terms of Human Development Index.

The high level of adult participation in some form of education or training (50-60\%) was recorded in Austria, Finland, Hungary, the United Kingdom, Germany, France, Denmark, and the lowest rates (less than 20\%) - in Serbia, Greece, Macedonia, Albania, Bosnia and Herzegovina, Romania.

In the first four leading countries, non-formal education covers more than $60 \%$ of adults, and the formal education (which is much more expensive) - only in Finland, Norway, Denmark, Sweden, the United Kingdom exceeds $10 \%$.

In most cases in the countries of the European Union, the development of adults was conducted in the areas of business, administration and law (17.2\%); health and welfare (15,9\%); services $(14.5 \%)$; arts and humanities (13.4\%); engineering, manufacturing and construction $(11.0 \%)$. The development of job-related knowledge and skills was the goal of non-formal education for $75.2 \%$ of women and $83.6 \%$ of men, the $86 \%$ and $89 \%$ of the cost of which respectively was sponsored by employer.

\subsection{Correlation analysis and clustering of EU countries} by indicators of lifelong learning

The results of the data analysis $[6,7,8,9,10,11,12,13]$ showed a high degree of feedback between the following indicators: Young people neither in employment nor in education and training and GDP per capita, PPP $(-0,6)$; Young people neither in employment nor in education and training and Adult participation in learning $(-0,67)$ and a high degree of direct communication between such indicators as: GDP per capita, PPP and Adult participation in learning $(0,69)$; GDP per capita, PPP and Tertiary educational attainment $(0,58)$; GDP per capita, PPP and Employment rates of recent graduates $(0,47)$ (table 1$)$. These relationships allow us to state that with the growth of the state welfare an increase in the value of education, particularly the education of adults; employment of the population also affects the growth of the number of adults who are learning, is observed.

To identify regional differences in the development of education during life in Europe, we will use the method of tree clustering of countries according to the above indicators (Figure 1). According to the results, we can identify 3 main groups (clusters) of countries in terms of lifelong learning indicators. Belgium and Germany are similar in the selected indicators; Austria and Iceland are then grouped together with Belgium and Germany. France and the United Kingdom; the Netherlands and Sweden; Northern Macedonia and Serbia are similar in all indicators, they are combined with Bulgaria and Romania; Portugal, Greece and the Czech Republic; Estonia and Slovakia; Croatia, Latvia, Hungary, Poland, Lithuania, Spain, Cyprus and Italy; Malta and Slovenia; Ireland, Switzerland, Luxembourg and Norway.

The results of K-Means clustering give the possibility to reveal the grouping of data and to conclude that the greatest contribution to the grouping of EU countries in such variables as: Young people neither in employment nor in education and training, $\%$ of population aged 15 to 29; Adult participation in learning $\%$ of population aged 25 to 64; Tertiary educational attainment, $\%$ of population aged 30 to 34; Employment rates of recent graduates, $\%$ of population aged 20 to 34 with at least upper-secondary education (F-statistics is greater than 3 and significance level is less than 5\%) (Table 2).

The group 1 includes 12 countries: Belgium, Bulgaria, Czech Republic, Germany, Spain, Latvia, Hungary, Malta, Poland, Portugal, Romania, Slovakia.

The group 2 includes 5 countries: Greece, Croatia, Italy, Macedonia and Serbia.

The group 3 includes 16 countries: Denmark, Estonia, France, Ireland, Lithuania, Luxembourg, the Netherlands, Austria, Slovenia, Finland, Sweden, the United Kingdom, Iceland, Norway and Switzerland.

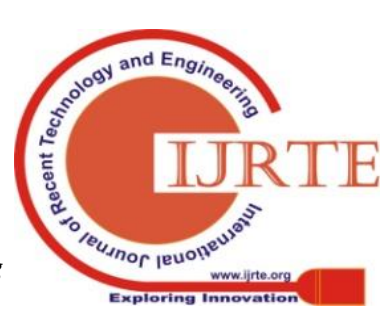


The next step is to build a distance matrix between clusters based on Euclidean distances. The group 3 is the most different from the other countries, because the distance between the $3^{\text {rd }}$ and $1^{\text {st }}$ group is 83 , between the $3^{\text {rd }}$ and $2^{\text {nd }}$ group - 363 (Fig.2.).

We can summarize that the average level of Young people neither in employment nor in education and training, \% of population aged 15 to 29 , is typical for 1 group of countries, while Adult participation in learning, $\%$ of population aged 25 to 64 does not exceed $10 \%$, Tertiary educational attainment, up to $40 \%$, and Employment rates of recent grades exceeds $80 \%$. The second cluster of countries is characterized by a higher (more than 20\%) level of Young people neither in employment nor in education and training, \% of population aged 15 to 29; the lowest level of Adult participation in learning among all countries, \% of population aged $25-64$ (about 5-6\%); the lowest levels of Tertiary educational attention (up to 30\%) and Employment rates of recent grades (up to $50 \%$ ). The third cluster is characterized by the lowest level of Young people neither in employment nor in education and training, \% of population aged 15 to 29 (within 10-12\%), a high level of Adult participation in learning, $\%$ of population aged 25 to 64 (about 20\%), high levels of Tertiary educational attendance (more than 50\%) and Employment rates of recent grades (more than $80 \%$ ).

Thus, in three clusters, significant differences were revealed regarding the participation of adults in education and the proportion of persons who received higher education at the age of 30-34 (their greatest involvement is determined in the group of cluster 3 countries in respect of clusters 1 and 2). The high level of employment of Employment rates of recent graduates, $\%$ of population aged 20 to 34 with at least upper-secondary education demonstrates the high demand for specialists who have received education in the countries of clusters 1 and 3 and the lower demand for specialists of cluster 2 .

\section{DISCUSSION}

1. The introduction of education for sustainable development requires governments to make informed political decisions on the implementation of reforms, ensuring their support by society. Paragraph 14 of the Framework for Action for the implementation of SDG 4 defines the need to allocate at least $4-6 \%$ of GDP and/or at least $15-20 \%$ of total public expenditure to education [2]. On the one hand, in conditions of insufficient funding for education, the allocation of funds is carried out on the basis of social justice rather than economic efficiency. In this case, the lowest levels of education are financed first. On the other hand, determining the effectiveness of educational policy on the basis of the cost principle does not provide reliable estimates of human capital development, because there is no proportional relationship between the costs and the results of education. In particular, according to the World Bank report, the correlation is due to the economic development of the country rather than the level of public spending, and more funding provides the highest quality of education only if it is used rationally with a focus on the result [4]. Therefore, the countries in cluster 2 need to reform the education of young people (the analysis of the lowest levels of education was not the purpose of our study). Taking into account the experience of the Netherlands, we propose to apply the following algorithm: a) identification of the main problems; b) identification of those tasks that can be solved by implementing pilot projects; c) analysis of foreign experience and determining the possibilities of its adaptation; d) implementation of experiments, determining the results of their implementation; e) use of the results of pilot projects to form strategies for all regions of the country.

2. For cluster 1, an important condition for the success of educational reforms is the high motivation of the target audience for training and development, a clear relationship between the level of professional competence and career development, wages and other opportunities. This task is difficult to implement in corrupt systems and low-income countries. In addition, it is important to be able to implement individual strategies for professional and personal development on flexible training schedules using ICT. The widespread introduction of non-formal adult education is ensured through the establishment of evaluation procedures and the formal recognition of its results.

3. Educational systems are inert, changes do not occur quickly, and the results of their implementation are postponed in time. This determines the complexity of monitoring and analysis of indicators, limits the possibility of their adjustment. Each country through the introduction of monitoring should create its own information system on the age and gender principle, in the context of types of education, methods of training and development, etc. At the same time, it is important to form not only quantitative, but also to justify the quality indicators of lifelong learning, which will be enhanced by the development of smart environment for adult education - this is a task for cluster 3 .

4. Focusing of adult education exclusively on job-related knowledge and skills reduces not only their competitiveness in the labor market, but also the functional ability to implement changes. After all, the key element and generator of changes is the processes of self-identification in the context of which there is a human personality. For the integrated implementation of the goals of sustainable development adult education should ensure the personal potential development, taking into account socio-cultural and psychological and mental characteristics of individuals. Unfortunately, Eurostat does not analyze such information, but personal qualities requirements are an important component of competence models in the private and public sectors of European countries. In particular, one of the three clusters of the public service of the United Kingdom is "engaging people", including: leading and communicating, building capacity for all, and collaborating. Therefore, monitoring and analysis of non-job-related knowledge and skills should be given due attention.

\section{CONCLUSION}

The analysis made it possible to cluster 33 European countries on the basis of indicators of continuous education and to substantiate proposals for three clusters on the formation of policy in the field of life education in the context of ensuring the implementation of sustainable development goals, namely: in cluster 1 - the policy of adult education should provide for the introduction of effective mechanisms of their motivation for professional development; in cluster 2

- in accordance with the principle of social justice, the priority is to determine the

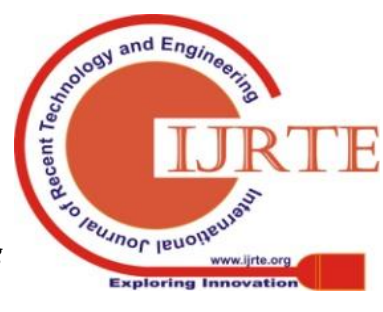


introduction of changes in the education of young people; in cluster 3 - to ensure the development of smart environment for adult education, systematic implementation of monitoring of quality indicators of life learning (further, this experience should be adapted by other countries).

\section{REFERENCES}

1. Lukianova, L. (2017), Legislative provision of adult education: foreign experience. Kyiv: TOV «DKS-Tsentr», [in Ukrainian]

2. Education-2030: The Incheon Declaration Framework for Action for the implementation of sustainable development goal 4. Retrieved from https://unesdoc.unesco.org/ark:/48223/pf0000245656

3. Orlović Lovren, V. \& Popović, K. (2018), Lifelong Learning for Sustainable Development - Is Adult Education Left Behind?, Handbook of Lifelong Learning for Sustainable development. Cham: Springer International Publishing AG, pg. 1-18

4. World Development Report 2018: Learning to Realize Education's Promise. Retrieved from http://www.worldbank.org/

5. Yakymets, M (2016), Methods of Clusterization and Their Classification. International Scientific Journal. Vol-6, issue 2, pg 48-50, [in Ukrainian]

6. Early leavers from education and training by sex Code: sdg_04_10, \% of population aged 18 to 24 . Retried from https://ec.europa.eu/eurostat/tgm/download.do?tab=table\&plugin=1\& language $=$ en $\&$ pcode $=$ sdg $\_4 \_10$

7. Adult learning statistics - characteristics of education and training Retried

from

https://ec.europa.eu/eurostat/statistics-explained/index.php/Adult_lea rning_statistics___characteristics_of_education_and_training\#Adult_ education_and_training:_relative_importance_of_formal_and_non-fo rmal_instruction

8. Employment rates of recent graduates by sex Code: sdg $04 \quad 50, \%$ of population aged 20 to 34 with at least upper-secondary education. Retried

https://ec.europa.eu/eurostat/tgm/table.do?tab=table\&init=1\&languag $\mathrm{e}=$ en\&pcode $=$ sdg $04 \quad 50 \&$ plugin $=1$

9. GDP per capita, PPP (current international \$). Retried from https://data.worldbank.org/indicator/NY.GDP.PCAP.PP.CD

10. Participation in early childhood education by sex Code: sdg_04_30,\% of the age group between 4-years-old and the starting age of compulsory education. Retried from https://ec.europa.eu/eurostat/tgm/table.do?tab=table\&init=1\&languag e=en\&pcode=sdg_04_30\&plugin $=1$

11. Tertiary educational attainment by sex Code: sdg_04_20, \% of population aged 30 to 34 . Retried from https://ec.europa.eu/eurostat/tgm/download.do?tab=table\&plugin=1\& language $=$ en\&pcode $=$ sdg_04_20

12. Underachievement in reading, maths or science (source: OECD) Code: sdg_04_40, \% of 15-year-old students. Retried from https://ec.europa.eu/eurostat/tgm/table.do?tab=table\&init=1\&languag $\mathrm{e}=\mathrm{en} \& \mathrm{pcode}=\mathrm{sdg} \_04 \_40 \&$ plugin $=1$

13. Young people neither in employment nor in education and training by se Code: sdg_08_20,\% of population aged 15 to 29 . Retried from https://ec.europa.eu/eurostat/tgm/table.do?tab=table\&init=1\&languag $\mathrm{e}=$ en\&pcode=sdg_08_20\&plugin $=1$

\section{AUTHORS PROFILE}

Buryk Zoriana, Doctor of science in Public Administration, senior lecturer of Regional management and Local Self-Government Department, Lviv Regional Institute for Public Administration of the National academy for Public Administration under the President of Ukraine

Orliv Mariana'Ph.D in Economics, docent of the Department of Public Administration and Management, Ivano-Frankivsk National Technical University of Oil and Gas

Karen Ismailov, Candidate of Juridical Sciences, Head of Department, Odessa State University of Internal Affairs

Department of Cyber security and information support

Corresponding author' ${ }^{1}$ Email: z.burik@ukr.net, $+3-80679994240$

Appendix

\begin{tabular}{|c|c|c|c|c|c|c|c|c|}
\hline Indicators & $\begin{array}{c}\text { YP } \\
\text { No } \\
\text { nE } \\
\text { mp } \\
\text { Nor } \\
\text { Ed } \\
\text { uc }\end{array}$ & $\begin{array}{l}\text { G } \\
\text { D } \\
\text { P }\end{array}$ & $\begin{array}{c}\text { PQ } \\
\text { Non } \\
\text { for } \\
\text { m }\end{array}$ & $\begin{array}{c}\text { Edu } \\
\text { cNo } \\
\text { nFo } \\
\text { rm }\end{array}$ & $\begin{array}{c}\text { Apa } \\
\mathbf{r}\end{array}$ & $\begin{array}{l}\text { Ele } \\
\text { ave }\end{array}$ & $\begin{array}{c}\text { Ter } \\
\mathbf{t}\end{array}$ & $\begin{array}{c}\text { Em } \\
\text { pRa } \\
\text { teR } \\
\text { ecG } \\
\text { rad }\end{array}$ \\
\hline $\begin{array}{l}\text { YPNonEm } \\
\text { pNorEduc }\end{array}$ & $\begin{array}{c}1,0 \\
0\end{array}$ & $\begin{array}{l}-0, \\
60 \\
\end{array}$ & $\begin{array}{c}-0,1 \\
6 \\
\end{array}$ & $\begin{array}{c}-0,0 \\
8 \\
\end{array}$ & $\begin{array}{c}-0,6 \\
7 \\
\end{array}$ & 0,03 & $\begin{array}{c}-0,5 \\
6\end{array}$ & $\begin{array}{c}-0,9 \\
2\end{array}$ \\
\hline GDP & $\begin{array}{c}-0,6 \\
0\end{array}$ & $\begin{array}{l}1, \\
00\end{array}$ & 0,08 & 0,11 & 0,69 & $\begin{array}{c}-0,1 \\
3\end{array}$ & 0,58 & 0,47 \\
\hline $\begin{array}{c}\text { PQNonfor } \\
\mathrm{m}\end{array}$ & $\begin{array}{c}-0,1 \\
6\end{array}$ & $\begin{array}{l}0, \\
08\end{array}$ & 1,00 & $\begin{array}{c}-0,0 \\
8\end{array}$ & 0,15 & 0,06 & 0,09 & 0,22 \\
\hline $\begin{array}{c}\text { EducNonF } \\
\text { orm }\end{array}$ & $\begin{array}{c}-0,0 \\
8\end{array}$ & $\begin{array}{l}0, \\
11\end{array}$ & $\begin{array}{c}-0,0 \\
8\end{array}$ & 1,00 & 0,13 & 0,02 & 0,11 & 0,04 \\
\hline Apar & $\begin{array}{c}-0,6 \\
7\end{array}$ & $\begin{array}{l}0, \\
69\end{array}$ & 0,15 & 0,13 & 1,00 & $\begin{array}{c}-0,0 \\
6\end{array}$ & 0,57 & 0,47 \\
\hline Eleave & $\begin{array}{c}0,0 \\
3\end{array}$ & $\begin{array}{l}-0, \\
13\end{array}$ & 0,06 & 0,02 & $\begin{array}{c}-0,0 \\
6\end{array}$ & 1,00 & $\begin{array}{c}-0,3 \\
2\end{array}$ & 0,10 \\
\hline Tert & $\begin{array}{c}-0,5 \\
6\end{array}$ & $\begin{array}{l}0, \\
58\end{array}$ & 0,09 & 0,11 & 0,57 & $\begin{array}{c}-0,3 \\
2\end{array}$ & 1,00 & 0,41 \\
\hline $\begin{array}{c}\text { EmpRateR } \\
\text { ecGrad }\end{array}$ & $\begin{array}{c}-0,9 \\
2\end{array}$ & $\begin{array}{l}0, \\
47\end{array}$ & 0,22 & 0,04 & 0,47 & 0,10 & 0,41 & 1,00 \\
\hline
\end{tabular}




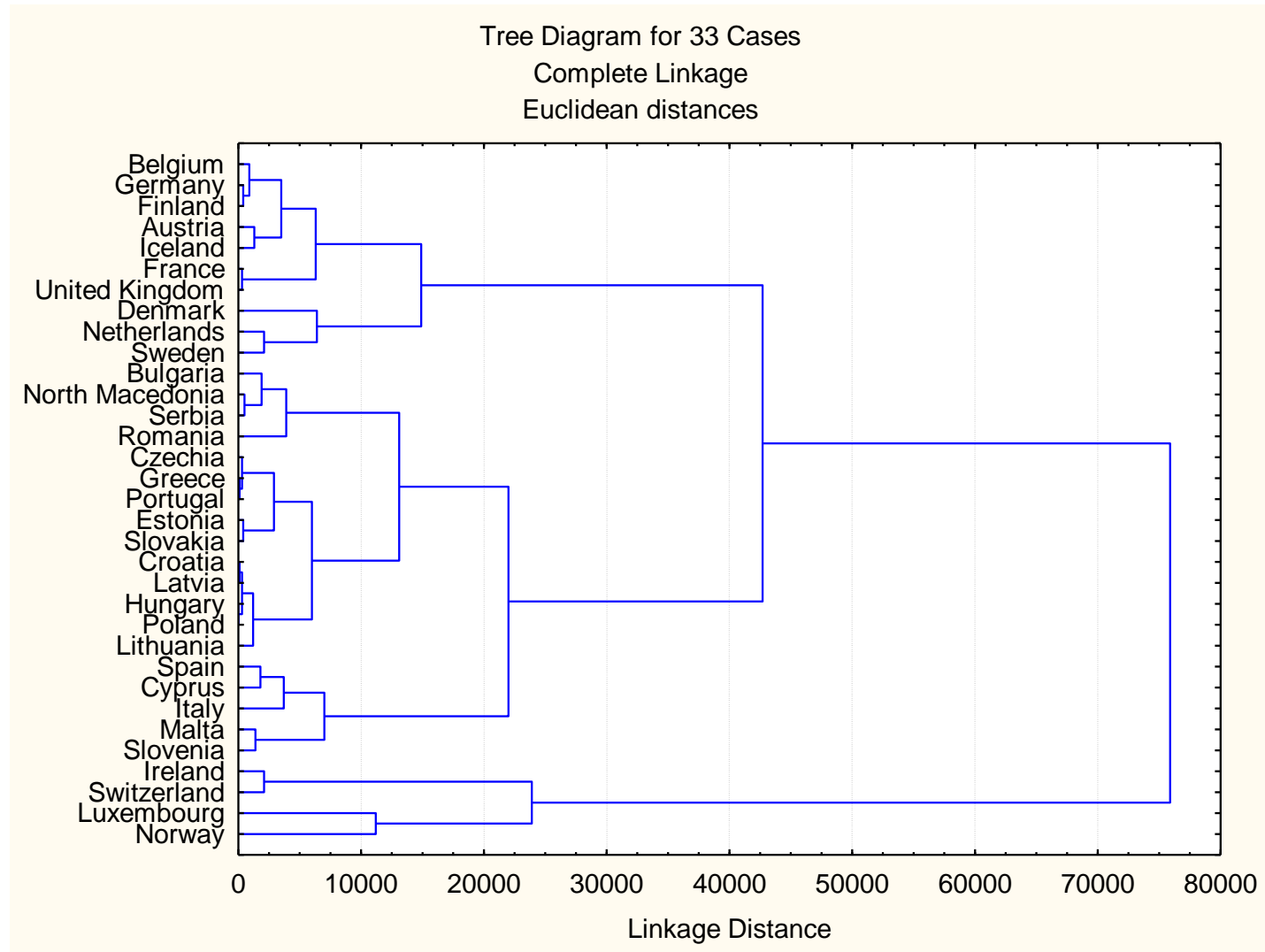

Table 2: Results of the significance of variables clustering

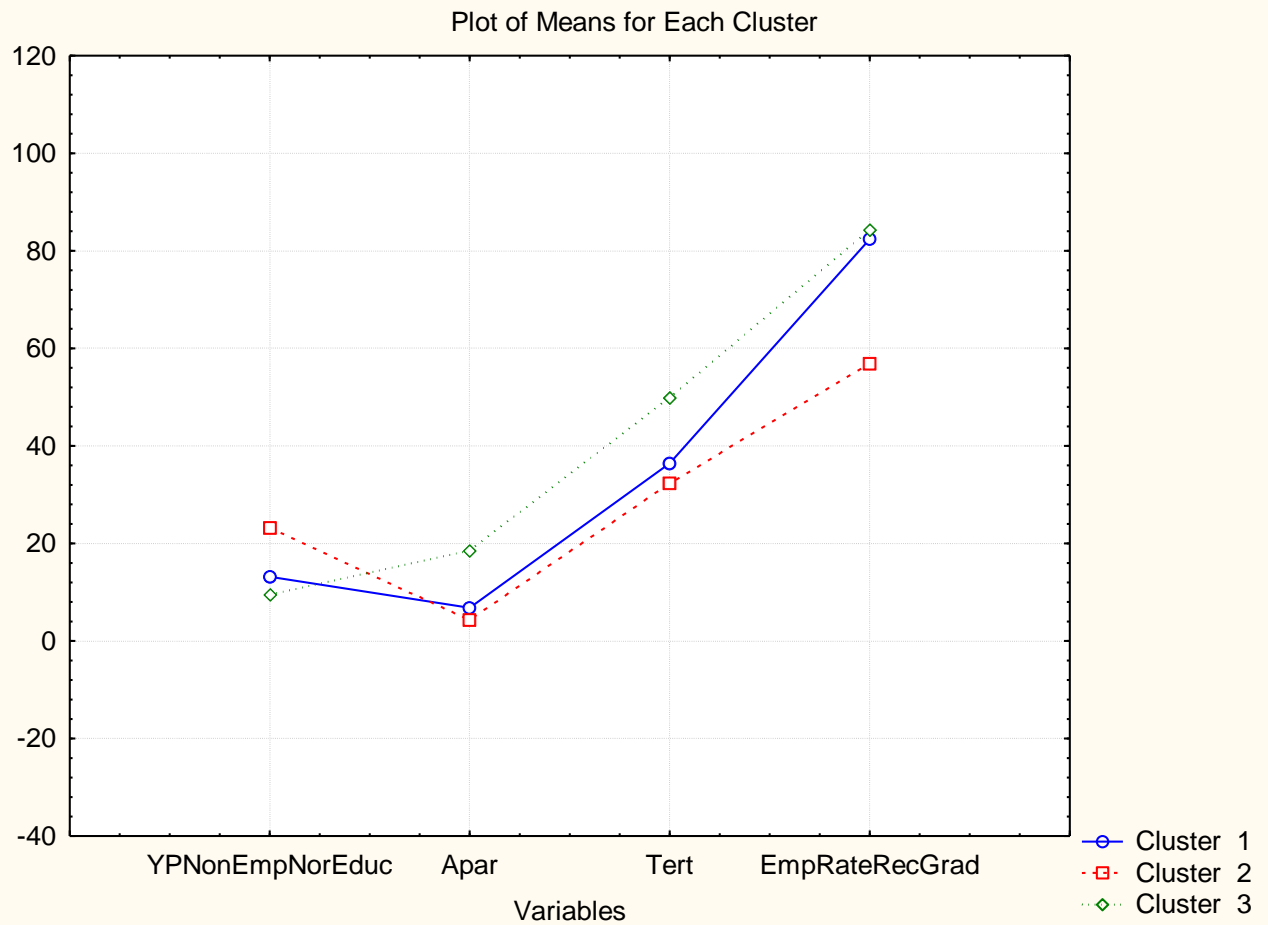

Figure 2: Graph of centroids (averages) and differences between countries according to the main classification indicators 